\title{
PRELIMINARY DESIGN AND EVALUATION OF STRATEGIC DASHBOARDS THROUGH THE TECHNOLOGY ACCEPTANCE MODEL
}

\author{
J.-M. Vasnier ${ }^{1, \bigotimes}$, N. Maranzana ${ }^{2}$, M. Messaadia ${ }^{1}$ and A. Aoussat ${ }^{2}$ \\ ${ }^{1}$ CESI - Lineact, France, ${ }^{2}$ Arts et Métiers ParisTech, France \\ 凶jmvasnier@cesi.fr
}

\begin{abstract}
In the age of the fourth industrial revolution, the competition between enterprises is fierce to operate efficiently and hold on to their customers. Due to lack of time and methodology, many leaders struggle to establish optimized strategies for their businesses. To do so, the key processes need to be measured using dashboards that proactively help decisions making, facilitate the strategy execution and keep the employees focused. The purpose of this article is to identify the design features of a risk analysis dashboard and their effects on the perceived ease of use and perceived usefulness.
\end{abstract}

Keywords: small and medium size enterprise (SME), case study, visualisation, strategic dashboard, technology acceptance model (TAM)

\section{Introduction}

In the age of the fourth industrial revolution, Small and Medium Enterprises (SMEs) are competing to improve their efficiency while retaining the interests of their customers. Unfortunately, many SME leaders have difficulties in establishing an optimized and coherent strategy due to lack of time, methodology and / or know-how. Too often, they react to changes in the environment by taking shortterm actions, without worrying too much about their relevance to the overall strategy, or the consequences that such decisions can have on the future development of their business (Grant, 2016). Also, the growth of a business depends on its ability to identify and adapt to its environment risks, and then continuously to measure the performance of its key processes. However, this process has little impact on a company's profitability unless employees interact with its visual display or performance dashboards and take actions based on the data collected (Velcu-Laitinen and Yigitbasioglu, 2012). Hence, a good fit between the usage and the dashboard design features, carefully implemented, should generate a positive predisposition among its users. Essentially, dashboards have a crucial role in helping the SME leader to navigate through the environment disturbances in much the same way that a plane's dashboard helps the pilot. Therefore, the purpose of this study is (i) to define the notion of risks identification and analysis; (ii) to show the impact of dashboard design features on the notions of perceived ease of use and perceived usefulness; and (iii) to identify the weight of each dashboard design features.

From these observations, emerged the following research question: What are the key features of a risk analysis dashboard and their effects on the two constructs: Perceived Usefulness and Perceived Ease of Use? In pursuit of this aim, the paper introduces the notions of dashboard, then the 
Technological Acceptance Model (TAM) is presented with its relevance to the design of dashboard. The proposed research model is introduced, followed by the research methodology, data analysis, results and research findings. Finally, the paper concludes by pointing out the future research directions.

\section{Outline}

\subsection{Dashboard}

The term dashboard comes from the dashboard of a vehicle as it presents the metrics that the driver needs to know. Similarly, dashboards also presents information from which managers and employees can visually identify trends, patterns and anomalies about the company (Yigitbasioglu and Velcu, 2012). Dashboards have three fundamental purposes: to monitor critical activities and processes using metrics that trigger alerts when performance falls short of established goals, to analyse the root causes of problems by exploiting relevant and timely data, to manage people and processes to improve decisions and lead the organization in the right direction (Eckerson, 2011). According to Tezel, the use of visual tools in a SME has multiple benefits such as improving transparency, facilitating routine job tasks, influencing people's behaviours, fostering continuous improvement, creating shared ownership, supporting management by facts, and removing organisational boundaries (Tezel et al., 2016).

\subsection{Dashboard design features}

Bititci presents a classification for dashboards, depending on the level (strategic or operational) and the theme (planning or progress) (Bititci et al., 2016). Dashboard are characterised by two types of design features: functional and visual features. Functional features allow a cognitive adjustment with different types of users, while the visual features refer to how efficiently and effectively information is presented to the user. Table 1 summarizes the dashboard design features identified in the literature (Abduldae and Gravell, 2019; Yigitbasioglu and Velcu, 2012; Brandy et al., 2017; Rahman et al., 2017).

Table 1. Summary of dashboard design features

\begin{tabular}{|l|r|}
\hline Functional features & Visual features \\
\hline $\begin{array}{l}\text { Format flexibility and interactivity (to be } \\
\text { able to display data in various formats and } \\
\text { at different levels of aggregation) }\end{array}$ & Display information on a single page \\
\hline Scenario analysis & High data to ink ratio \\
\hline Real-time notifications and alerts & Use of grid lines for 2D and 3D graphs \\
\hline Format type (graphs vs tables) & $\begin{array}{r}\text { Frugal use of colours (prefer intensity) } \\
\text { and keep graphical icons sparse }\end{array}$ \\
\hline Drill-down capabilities & $\begin{array}{r}\text { Improve the context of metrics } \\
\text { (performance state, trend and variance) }\end{array}$ \\
\hline
\end{tabular}

\subsection{Technology Acceptance Model (TAM)}

Technology Acceptance Model (TAM) was introduced by Fred Davis in 1986 and it is specifically tailored for modeling users' acceptance of information systems or technologies. Dashboards can be designed in a variety of ways, in our case the user wants to get specific piece of information about the results of the risk analysis and uses the dashboard to obtain it. As a result, the design and the visualization style must respond to some aspects of TAM (Janes et al., 2013). TAM is built on the Theory of Reasoned Action, positioning Perceived Usefulness (PU) and Perceived Ease Of Use (PEOU) as the main determinants of Behaviour Intention (BI) (as shown in Figure 1). Perceived Usefulness is defined as "the degree to which a person believes that using a particular system would enhance his or her performance" (Davis et al., 1989). Perceived Ease Of Use refers to "the degree to which a person believes that using a particular system would be free of effort" (Davis et al., 1989). 


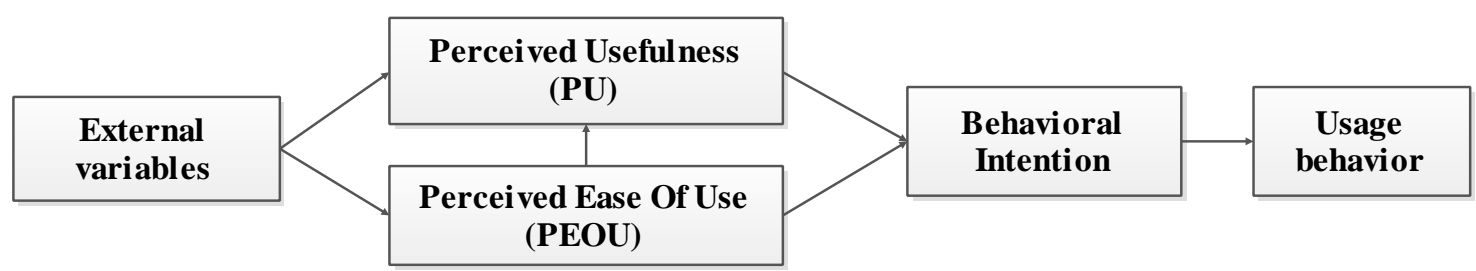

Figure 1. Technology Acceptance Model (Venkatesh and Davis, 1996)

PU and PEOU have demonstrated high reliability, validity (Venkatesh and Davis, 1996) and have received empirical support for being robust in predicting technology adoption for a variety of technologies such as ERP, E-payment, driving assistance systems or Dashboard Design (Janes et al., 2013). The literature review has revealed that the evaluation of dashboard using the Technology Acceptance Model is scarce (Rahman et al., 2017) hence the need to identify if the TAM framework is an appropriate tool for assessing employee's acceptance of a risk analysis dashboard.

\subsection{Assessing the SME environment and level of risks}

The literature review highlights the fact that SMEs suffer from limited human and financial resources and their inability to effectively manage all risks at the same time (Sukumar et al., 2011). It is therefore advisable for SMEs to identify all potential risks, then focus on the most critical ones and train their employees to manage these risks.

\subsubsection{Risks identification}

The causes of entrepreneurial failure are multiple and linked to external (or exogenous) factors, which the company does not control, and / or to internal (or endogenous) factors specific to the company individuals (Coulibaly, 2004). Internal factors involve the resources and capabilities of the company, while external factors integrate macro and competitive environments. The competitive environment is where the SME buys, sells to its customers the goods or services it produces, and competes with competitors that produce similar goods. The macro environment is the set of political, economic, social, technological, legal and environmental factors that directly or indirectly affect the operations of the company. The complete SME environment risk factors are shown in Table 2.

Table 2. The SME environment risk factors

\begin{tabular}{|l|c|r|}
\hline Macro Environment & Competitive Environment & Internal Environment \\
\hline Legal & Buyer Power & Inbound logistics \\
\hline Environmental & Rivalry & Operations \\
\hline Social & Substitutes & Outbound logistics \\
\hline Economic & New entrants & Marketing \& Sales \\
\hline Technological & Supplier Power & Services \\
\hline Political & & Firm infrastructure \\
\hline & & HR management \\
\hline & & Technology \\
\hline
\end{tabular}

\subsubsection{Strategic dimensions}

To formalize and monitor the implementation of its strategy, SMEs use Performance Measurement Systems (PMS) (Gimbert et al., 2010). One of the most popular PMS tool is the Balanced Scorecard (Kaplan and Norton, 1996) used by more than $50 \%$ of the companies in North America. PMS has to not only ensure that stakeholders needs, strategy and companies objectives remains aligned through interactive dashboards, but also be responsive to changes in the SME environments (Grant, 2016). To do so, the impact of all risk factors on each strategic dimension need to be identified and combined with the leader vision, so that the SME leader can create a sustainable competitive advantage that is difficult for competitors to overcome (Vasnier et al., 2019). The most known dimensions of performance 
are: quality, flexibility, cost and time. From the survey, we have identified up to seven other dimensions: finance, human resources, product innovation, supplier relations, environmental performance, community and alliances (Table 3 ).

Table 3. The proposed main strategic dimensions

\begin{tabular}{|c|c|}
\hline 1 & Product and Services Quality (defect rates, quality awards) \\
\hline 2 & Operational Performance (productivity, safety, cycle time) \\
\hline 3 & Finance (annual earnings, return on assets, cost reduction) \\
\hline 4 & Customer Relation (market share, customer satisfaction, customer retention) \\
\hline 5 & $\begin{array}{c}\text { Human Resources / Employee Relations (employee satisfaction, turnover, workforce } \\
\text { capabilities) }\end{array}$ \\
\hline 6 & $\begin{array}{c}\text { Product and Services Innovation (new product or service development success, development } \\
\text { cycle time) }\end{array}$ \\
\hline 7 & Supplier Relations (on time delivery, input into product/service design) \\
\hline 8 & Alliances with other Organizations (joint marketing or product design, joint-ventures) \\
\hline 9 & Environmental Performance (environment compliance or certification) \\
\hline 10 & Community (public image, community involvement) \\
\hline
\end{tabular}

\subsubsection{Quantifying the level of risks}

The "fear of harm ought to be proportional not merely to the gravity of the harm, but also to the probability of the event", as mentioned by Antoine Arnauld in 1662 in a monastic publication entitled: Logic, or the Art of Thinking. Nowadays, the notion of risk is defined as, "the chance of something happening that will have an impact on objectives". In other words, the risk assessment process requires the assessment of the likelihood of each risk and its impact. The risk factor is defined as (Equation 1):

$$
\mathrm{R}=\mathrm{P} \times \mathrm{I}
$$

where $\mathrm{R}$ is the risk factor, $\mathrm{P}$ is the likelihood (probability), I is the impact (severity).

Each environment risk factor (Table 2) is assessed to determine its likelihood and impact on each strategic dimension (Table 3). The risk factor is then assigned to a specific zone L (low), M (medium) or $\mathrm{H}$ (high) according to its value either negative (threat) or positive (opportunity). The zones: L-, M-, or $\mathrm{H}-$ represent low, medium, or high threat zones, and $\mathrm{L}+, \mathrm{M}+$, or $\mathrm{H}+$ identify low, medium, and high opportunity zones. The identification of each zone by using the guideline shown in Table 4 reduces the bias related to the interpretation of a simple numerical value and replies to the three axioms of a welldefined risk matrix (Cox, 2008).

Table 4. Threats and opportunities zones identification

\begin{tabular}{|c|c|c|c|}
\hline Risk factor value & Strength & Threats & Opportunities \\
\hline$<-45$ & High & H- & \\
\hline$<-9$ and $>=-45$ & Medium & M- & \\
\hline$>=-9$ & Low & L- & \\
\hline$>+45$ & High & & H+ \\
\hline$>+9$ and $<=+45$ & Medium & & M+ \\
\hline$<=+9$ & Low & & L+ \\
\hline
\end{tabular}

\subsubsection{Identifying the score on each strategic dimension}

In an environment risk analysis, all factors are often considered equally important, but it must be taken into account that most factors do not have the same weighting (Louw and Radder, 1998). To overcome this disadvantage, we will use the Analytical Hierarchy Process (AHP), which is a multi-criteria and weighted decision-making method proposed by Saaty (Saaty, 2008). AHP enables to highlight the relationships that exist among the environmental risk factors for each one of the ten strategic dimensions (Vasnier et al., 2019). 


\section{Proposed research model and hypotheses}

In accordance to the research objective and consistent with the related literature, this study examined the following hypotheses:

- H1: Perceived Ease Of Use (PEOU) will have a significant influence on Perceived Usefulness (PU)

- H2: Dashboard Strategic Features (DSF) has a positive effect on Perceived Usefulness (PU)

- H3: Dashboard Strategic Features (DSF) has a positive effect on Perceived Ease Of Use (PEOU)

A successful strategy must include two main characteristics: the ability to quickly assess and adapt to an ever-changing environment through a risk analysis, and a communication tool that is understandable by all employees. In order to bring a response to those specific features, the conceptual framework shown in Figure 2 identifies the key features of a risk analysis dashboard and their effects on the two factors: Perceived Usefulness and Perceived Ease of Use.

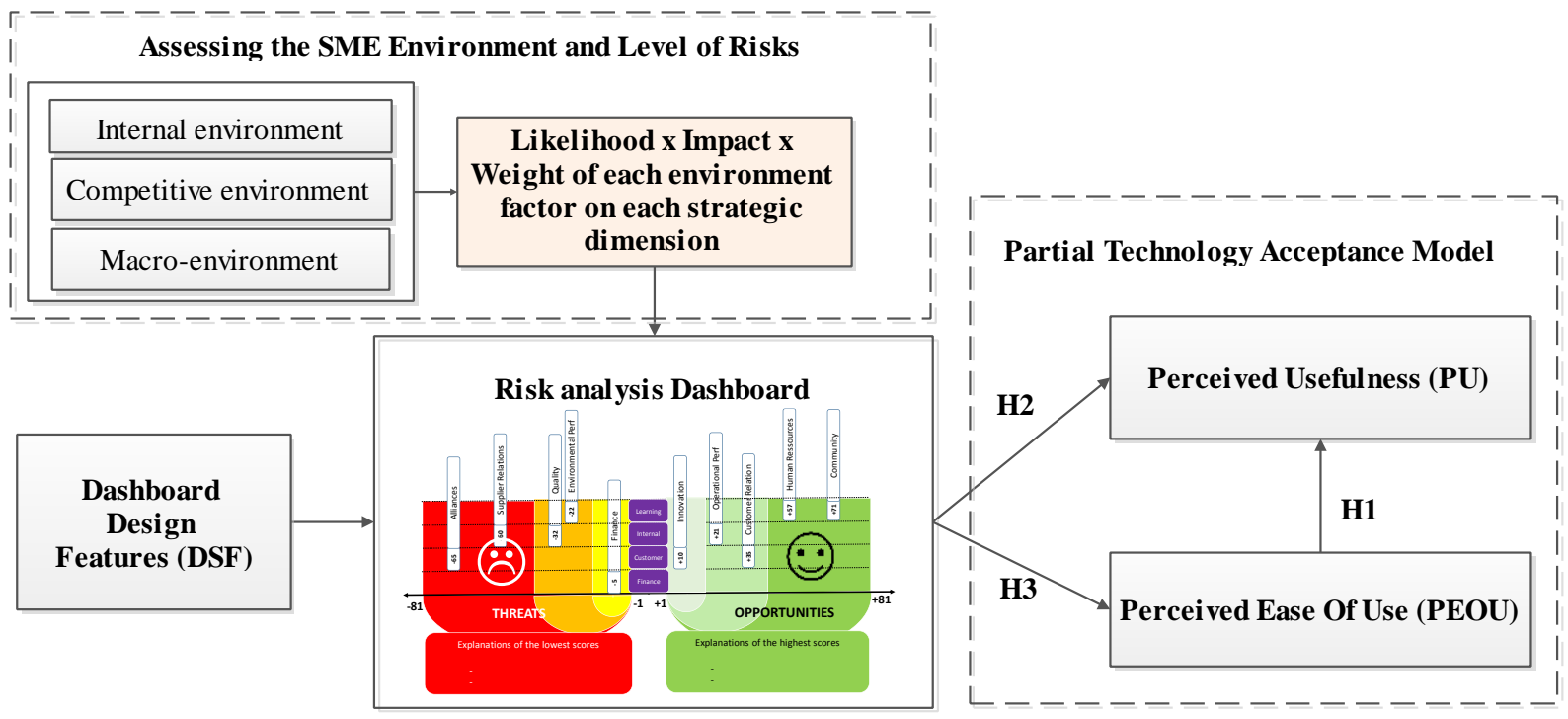

Figure 2. Proposed design dashboard model

\section{Case study}

\subsection{Questionnaire design}

A group of 14 mature students (86\% male, 14\% female) with a mean age of 37 years (SD 7.5 years) were asked to design dashboards to represent the results of the risk analysis on each strategic dimension (Table 3). All dashboards were then presented to the group of students and they selected the twelve most successful designs (Figure 3). To limit the self-selection bias and conflict of interest, the survey was then distributed to several groups of mature students $(n=61)$. A response rate of $51 \%(\mathrm{n}=31)$ was obtained ( $87 \%$ male, $13 \%$ female) with a mean age of 34 years (SD 9 years). All respondents quoted each dashboard design based on the survey items shown in Table 5 . All the students who took part to this study were enrolled in a Master of Engineering (MEng) programme at CESI Campus Ouest, France.

The survey items are designed to capture the three constructs in the Proposed Design Dashboard Model (Figure 2): Dashboard Design Features (DSF), Perceived Usefulness (PU) and Perceived Ease Of Use (PEOU). Table 5 shows the grouping of the items under each construct. The TAM questionnaire was derived from (Davis et al., 1989), (Surendran, 2012), and (Scholtz et al., 2016) for measuring PU and PEOU. 


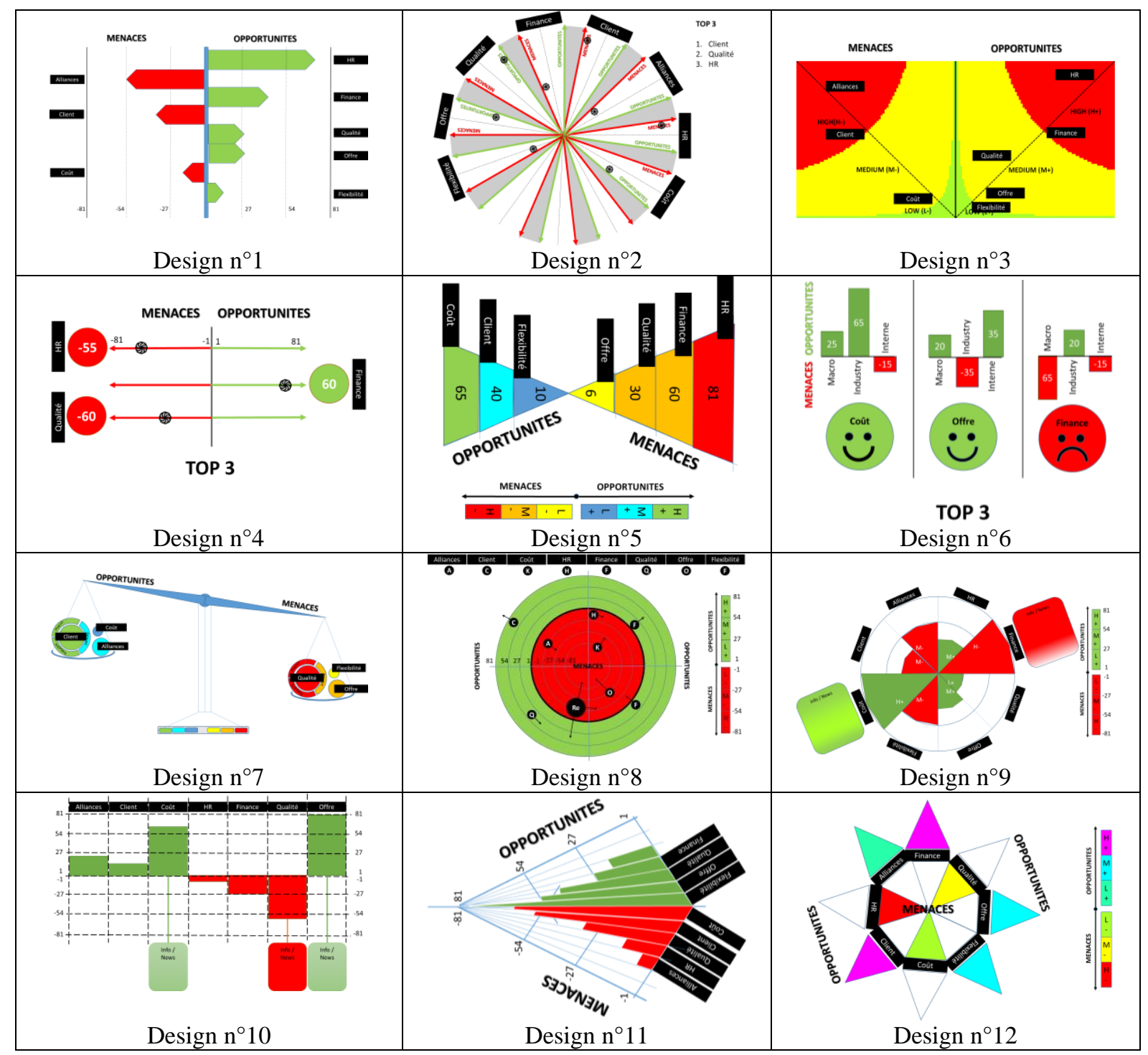

Figure 3. The panel of risk analysis dashboards

Table 5. Survey items

\begin{tabular}{|l|l|l|}
\hline Construct & Items & Survey items \\
\hline \multirow{4}{*}{$\begin{array}{l}\text { Perceived } \\
\text { Usefulness } \\
\text { (PU) }\end{array}$} & PU1 & This dashboard is effective in presenting the threats and the opportunities? \\
\cline { 2 - 3 } & PU2 & Does the dashboard increase employee collaboration? \\
\cline { 2 - 3 } & PU3 & $\begin{array}{l}\text { The dashboard makes it possible to limit misunderstandings between the } \\
\text { management and the employees? }\end{array}$ \\
\cline { 2 - 3 } & PU4 & Does the dashboard increase the efficiency of employees? \\
\cline { 2 - 3 } & PU5 & Overall, I find that the dashboard is useful? \\
\hline \multirow{3}{*}{$\begin{array}{l}\text { Perceived } \\
\text { Ease of } \\
\text { Use } \\
\text { (PEOU) }\end{array}$} & PEOU1 & The dashboard is easy to understand and interpret? \\
\cline { 2 - 3 } & PEOU2 & The interaction with the dashboard is simple and clear? \\
\cline { 2 - 3 } $\begin{array}{l}\text { Dashboard } \\
\text { Design }\end{array}$ & PEOU3 & The dashboard is easy to learn? \\
\cline { 2 - 3 } $\begin{array}{l}\text { Features } \\
\text { (DSF) }\end{array}$ & PEOU4 & The use of the dashboard requires little effort? \\
\cline { 2 - 3 } & PEOU5 & Overall, the dashboard is easy to use? \\
\cline { 2 - 3 } & DSF2 & Do the scores are prioritized? \\
\cline { 2 - 3 } & DSF3 & Does each score is quantify by a number, a letter or other? \\
\cline { 2 - 3 } & DSF4 & Does each score is strengthened by visual elements? \\
\cline { 2 - 3 } & DSF5 & Does each score is interpretable using a global scale? \\
\hline
\end{tabular}


The Dashboard Design Features originated from the recommendations of Table 1. All items were measured using a labelled seven-point Likert scale: Responses were coded from 1 (for 'Strongly Disagree') to 7 (for 'Strongly Agree'), so higher ratings indicated more positive attitudes.

\subsection{Data analysis}

The SmartPLS Version 3.0 software was used to analyze the data gathered from the survey. SmartPLS is one of the prominent software applications for Partial Least Squares Structural Equation Modeling (PLS-SEM). It has been deployed in many fields, such as behavioral sciences, marketing, organization and business strategy. Following the recommendations by other researchers (Chin, 2010) the bootstrapping method (500 resample) was used to determine the significance levels of loadings, weights, and path coefficients.

\subsection{Results and analysis}

The minimum sample size was identified at $n=70$ by using the guidelines of Marcoulides and Saunders (2006), with a significance level of $5 \%$, a statistical power of $80 \%, \mathrm{R}^{2}$ values of at least 0.25 and a maximum number of arrows pointing at a latent variable of 5 . The descriptive statistics of the three-construct items are shown in Table 6. All means are above the midpoint of 3.00. The wide range of risk analysis dashboards, which were analysed, are all of various design and their impact on the constructs: PU, PEOU and DSF were assessed using the Likert scale. That explain the medium spread of standard deviations on the three constructs (from 1.425 to 1.969).

Table 6. Summary of means and standard deviations

\begin{tabular}{|l|l|r|}
\hline Items & Mean & Standard deviation \\
\hline PU1 & 4.446 & 1.915 \\
\hline PU2 & 3.716 & 1.488 \\
\hline PU3 & 3.802 & 1.616 \\
\hline PU4 & 3.593 & 1.425 \\
\hline PU5 & 3.749 & 1.785 \\
\hline PEOU1 & 4.142 & 1.882 \\
\hline PEOU2 & 4.006 & 1.848 \\
\hline PEOU3 & 4.145 & 1.804 \\
\hline PEOU4 & 4.084 & 1.785 \\
\hline PEOU5 & 4.031 & 1.856 \\
\hline DSF1 & 4.571 & 1.913 \\
\hline DSF2 & 3.777 & 1.969 \\
\hline DSF3 & 4.443 & 1.915 \\
\hline DSF4 & 5.106 & 1.560 \\
\hline DSF5 & 4.696 & 1.813 \\
\hline
\end{tabular}

In Table 7, the Average Variance Extracted (AVE) and Composite Reliability (CR) measures of the three 1st order constructs are reported. The measurements are acceptable if the AVE for each construct is greater than 0.50 and CR is greater than 0.70 (Hair et al., 2011). In this case, all items are loaded highly on their own latent variable, and thus all measurements have satisfactory levels of reliability.

Table 7. Construct reliability and validity of 1 st order constructs

\begin{tabular}{|l|c|c|}
\hline & CR & AVE \\
\hline Perceived usefulness (PU) & 0.964 & 0.844 \\
\hline Perceived ease of use (PEOU) & 0.966 & 0.850 \\
\hline Dashboard design features (DSF) & 0.865 & 0.568 \\
\hline
\end{tabular}


The second order constructs (Table 8) show that the VIF values for the Dashboard Design Features are all below the threshold of 3.33 (Diamantopoulos and Siguaw, 2006). The results therefore did not indicate a multicollinearity problem. Using a two-tailed t-test with a significance level of 5\%, the path coefficient will be significant if the T-statistics is larger than 1.96. The t-value for the outer weights of item DSF2 is lower than 1.96, suggesting that the path coefficient is not significant. However, the significance of the outer loading is 9.197 for DSF2 showing that it cannot be removed from the analysis.

Table 8 . Construct reliability and validity of 2 nd order constructs

\begin{tabular}{|l|c|c|c|r|}
\hline Usability & Weights & $\mathrm{t}$ value & $\mathrm{p}$ value & VIF \\
\hline DSF1 & 0.175 & 2.301 & 0.022 & 1.707 \\
\hline DSF2 & 0.001 & 0.009 & 0.993 & 1.497 \\
\hline DSF3 & 0.272 & 3.215 & 0.001 & 2.035 \\
\hline DSF4 & 0.501 & 6.980 & 0.000 & 1.751 \\
\hline DSF5 & 0.270 & 3.492 & 0.001 & 1.665 \\
\hline
\end{tabular}

This study employed a structural equation modeling approach to develop a model that represents the relationships among the three constructs in this study: Perceived Usefulness (PU), Perceived Ease Of Use (PEOU), and Dashboard Design Features (DSF) as shown in Figure 4.

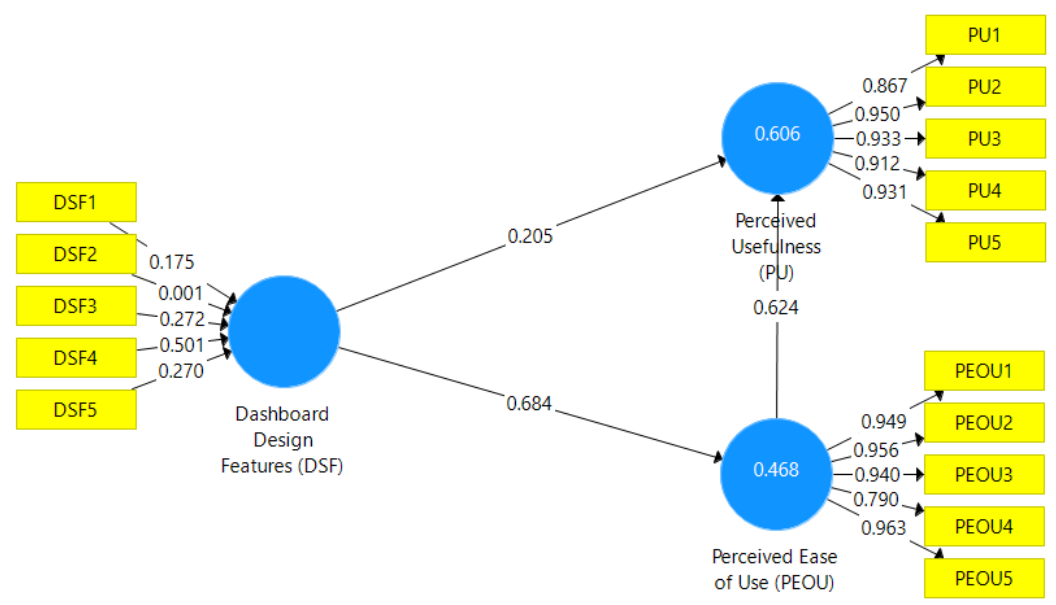

Figure 4. Results of the structural model (from SmartPLS)

Table 9 presents the results of the hypotheses tests by confirming the presence of a statistically significant relationship in the predicted direction of the proposed research model.

Table 9. Hypotheses testing results

\begin{tabular}{|l|c|c|c|c|r|}
\hline Hypothesis & Relation & Path co-efficient & t value & p value & Result \\
\hline H1 & PEOU $\rightarrow$ PU & 0.624 & 13.313 & 0.000 & supported \\
\hline H2 & DSF $\rightarrow$ PU & 0.205 & 4.584 & 0.000 & supported \\
\hline H3 & DSF $\rightarrow$ PEOU & 0.684 & 23.369 & 0.000 & supported \\
\hline
\end{tabular}

Statistically, significant support is found for H1 (PEOU $\rightarrow$ PU, $\beta=0.624, p<0.01$ ), and this confirms previous studies reporting a positive effect of PEOU on PU. Our study highlighted significant evidence supporting hypotheses $\mathrm{H} 2(\beta=0.205, \mathrm{p}<0.01)$ and $\mathrm{H} 3(\beta=0.684, \mathrm{p}<0.01)$ which address the positive impact of the dashboard design features on the factors PU and PEOU. The structural model shows that the three key design features of a dashboard are: Use of visual elements (DSF4), the quantification of each score (DSF3) and the use of a scale (DSF5).

\subsection{Findings and discussion}

At the time of writing, no previous evidence could be found on the impact of risk analysis Dashboard Design features on PU and PEOU. Hypothesis H1 is supported, i.e. Perceived Ease of Use has a 
significant influence on Perceived Usefulness, which is in agreement with numerous applications of TAM in technological applications (such as ERP, GPS or driver acceptance system). Hypotheses $\mathrm{H} 2$ and H3 are supported, i.e. the Dashboard Design Features (DSF) have a strong positive effect on PEOU and PU. Furthermore, the survey scores of the dashboard design features: DSF1 to DSF5 for each Dashboard Design timed by its weight (Table 8) enable to identify the three best dashboard designs (Table 10).

Table 10. Risk analysis dashboard scores

\begin{tabular}{|c|c|c|c|c|c|}
\hline Design $^{\circ} 1$ & 5.172 & Design $n^{\circ} 2$ & 5.269 & Design $n^{\circ} 3$ & $\mathbf{6 . 6 4 4}$ \\
\hline Design $^{\circ} 4$ & 6.040 & Design $n^{\circ} 5$ & 5.189 & Design $n^{\circ} 6$ & 6.394 \\
\hline Design $^{\circ} 7$ & $\mathbf{6 . 8 8 3}$ & Design $n^{\circ} 8$ & 6.590 & Design $n^{\circ} 9$ & 3.937 \\
\hline Design $^{\circ} 10$ & 5.057 & Design $n^{\circ} 11$ & $\mathbf{6 . 7 3 8}$ & Design $n^{\circ} 12$ & 5.915 \\
\hline
\end{tabular}

Finally, this paper has identified that out of the five Dashboard Design Features, only DSF2 failed the significance test. Also, to ensure that a risk analysis dashboard is easy to use and useful for all employees, we should only focus our attention to the features (DSF1 to DSF5) with high outer weights.

\section{Conclusion and further work}

This preliminary study made several theoretical contributions to the field of risk analysis dashboard. It is interesting to note that the study showed that dashboard design can positively affect the users' Perception of Usefulness and Ease of Use. Specifically, it identifies that the notions of quantification, use of visual elements and use of a scale are the main dashboard design factors. This study did not focus on the "voice of the workers" opinions about the design and use of a risk analysis dashboard. Therefore, further research is required to assess the workers' point of view, thus avoiding possible bias of employee from middle or senior management. Another issue still to investigate is the use of colour intensity instead of hue to accommodate colour-blind workers, as most of whom cannot differentiate between red and green. Finally, some further investigation are required to identify if the Perceived Usefulness and Perceived Ease of Use have a direct influence on the Intention to Use a risk analysis dashboard. Risk analysis dashboards sit at the crossroads of strategy formalization, data-capture, and decision-making. Chunka Mui and Paul Carroll in their book published in 2009 and entitled the "Billion dollar lessons", identified that $46 \%$ of failures in 750 large companies resulted from poorly developed strategies. A carefully designed and deployed strategic dashboards can provide incisive strategic insight, improve decision making, and enhance both alignment and implementation of the strategy across the SME entity.

\section{Acknowledgements}

We are grateful to Dr Norlaily Yaacob, Coventry University, UK for her comments that greatly improved the quality of this article.

\section{References}

Abduldaem, A. and Gravell, A. (2019), "Principles for the Design and Development of Dashboards: Literature Review", Proceedings of INTCESS 2019 - 6th International Conference on Education and Social Sciences, 4-6 February 2019, Dubai.

Bititci, U., Cocca, P. and Ates, A. (2016), "Impact of visual performance management systems on the performance management practices of organisations", Int. J. Prod. Res, Vol. 54, pp. 1571-1593. https://doi.org/10.1080/00207543.2015.1005770

Brandy, A. et al. (2017), "Proposal for a new usability index for product design teams and general public", Proceedings of the 21st International Conference on Engineering Design (ICED17), Vol. 8, Human Behaviour in Design, Vancouver, Canada, 21-25.08.2017. https://doi.org/10.1080/09544820310001617711

Chin, W.W. (2010), Bootstrap cross-validation indices for PLS path model assessment, V. Esposito Vinzi et al. (eds.) Handbook of Partial Least Squares, pp. 83-97, Springer Handbooks. https://doi.org/10.1007/978-3540-32827-8_4

Coulibaly, A.D. (2004), "La défaillance des PME belges: Analyse des déterminants et modélisation statistique" No. 437, Unpublished doctoral dissertation, Presses univ. de Louvain.

Cox Jr., L.A. (2008), "What's wrong with risk matrices?", Risk Analyis, Vol. 28 No. 2, pp. 497-512. https://doi.org/10.1111/j.1539-6924.2008.01030.x 
Davis, F.D., Bagozzi, R.P. and Warshaw, P.R. (1989), "User acceptance of computer technology: A comparison of two theoretical models", Management Science, Vol. 35 No. 8, pp. 982-1003. https://doi.org/ $10.1287 / \mathrm{mnsc} .35 .8 .982$

Diamantopoulos, A. and Siguaw, J.A. (2006), "Formative versus reflective indicators in organizational measure development: A comparison and empirical illustration”, British Journal of Management, Vol. 17 No. 4, pp. 263-282. https://doi.org/10.1111/j.1467-8551.2006.00500.x

Eckerson, W.W. (2011), Performance Dashboards: Measuring, Monitoring, and Managing Your Business, Second Ed., John Wiley \& Sons, New Jersey. https://doi.org/10.1002/9781119199984

Gimbert, X., Bisbe, J. and Mendoza, X. (2010), "The Role of Performance Measurement Systems in Strategy Formulation Processes", Long range Planning, Vol. 43 No. 4, pp. 477-497. https://doi.org/10.1016/ j.lrp.2010.01.001

Grant, R.M. (2016), Contemporary strategy analysis, Text and cases edition, John Wiley \& Sons.

Hair, J.F., Ringle, C.M. and Sarstedt, M. (2011), "PLS-SEM: Indeed a silver bullet", Journal of Marketing Theory and Practice, Vol. 19 No. 2, pp. 139-152. https://doi.org/10.2753/mtp1069-6679190202

Janes, A., Sillitti, A. and Succi, G. (2013), "Effective dashboard design", Cutter IT Journal, Vol. 26 No. 1, pp. 17-24.

Kaplan, R.S. and Norton, D.P. (1996), "Using the balanced scorecard as a strategic management system", Harvard Business Review, Vol. 74, Jan-Feb 1996, pp. 75-85. https://doi.org/10.4236/jss.2016.411004

Louw, L. and Radder L. (1998), "The SPACE Matrix: A Tool for Calibrating Competition", Long Range Planning, Vol. 31 No. 4, pp. 549-559. https://doi.org/10.1016/s0024-6301(98)80048-4

Marcoulides, G.A. and Saunders, C. (2006), “Editor's comments - PLS: A Silver Bullet?", MIS Quarterly, Vol. 30 No. 2, pp. iii-ix. https://doi.org/10.2307/25148727

Rahman, A.A., Adamu, Y.B. and Harun, P. (2017), "Review on dashboard application from managerial perspective", In 2017 International Conference on Research and Innovation in Information Systems (ICRIIS), IEEE, pp. 1-5. https://doi.org/10.1109/icriis.2017.8002461

Saaty, T.L. (2008), "Decision making with the analytic hierarchy process", International journal of services sciences, Vol. 1 No. 1, pp. 83-98. https://doi.org/10.1504/ijssci.2008.017590

Scholtz, B., Mahmud, I. and Ramayah, T. (2016), "Does usability matter? An analysis of the impact of usability on technology acceptance in ERP settings", Interdisciplinary Journal of Information, Knowledge, and Management, Vol. 11, pp. 309-330. https://doi.org/10.28945/3591

Sukumar, A., Edgar, D. and Grant, K. (2011), “An investigation of e-business risks in UK SMEs, World Review of Entrepreneurship", Management and Sustainable Development, Vol. 7 No. 4, pp. 380-401. https://doi.org/10.1504/wremsd.2011.042892

Surendran, P. (2012), “Technology acceptance model: A survey of literature”, International Journal of Business and Social Research (IJBSR), Vol. 2 No. 4, pp. 175-178. https://doi.org/10.18533/ijbsr.v2i4.161

Tezel, A., Koskela, L. and Tzortzopoulos, P. (2016), "Visual management in production management: a literature synthesis", Journal of manufacturing technology management, Vol. 27 No. 6, pp. 766-799. https://doi.org/10.1108/jmtm-08-2015-0071

Vasnier, J.M. et al. (2019), "Efficient identification model of strategic key dimensions in SMEs", Proceedings of the International conference on Industrial Engineering and Operations Mangement, Dubai, March 10-13, 2019. (To be published)

Velcu-Laitinen, O. and Yigitbasioglu, O.M. (2012), "The Use of Dashboards in Performance Management: Evidence from Sales Managers", International Journal of Digital Accounting Research, Vol. 12, pp. 36-58. https://doi.org/10.4192/1577-8517-v12_2

Venkatesh, V. and Davis, F.D. (1996), "A model of the antecedents of perceived ease of use: Development and test”, Decision Sciences, Vol. 27 No. 3, pp. 451-481. https://doi.org/10.1111/j.1540-5915.1996.tb01822.x

Yigitbasioglu, O.M. and Velcu, O. (2012), "A review of dashboards in performance management: Implications for design and research", International Journal of Accounting Information Systems, Vol. 13 No. 1, pp. 41-59. https://doi.org/10.1016/j.accinf.2011.08.002 